\title{
Chronic headache among general practice out patients in a tertiary care hospital, Eastern Nepal
}

\author{
R Bhandari ${ }^{1}$, R Bhandari ${ }^{1}$, DR Shakya ${ }^{2}$, R Maskey $^{3}$, M Paudel $^{1}$, R Giri ${ }^{1}$, PP Gupta ${ }^{1}$ \\ Department of General Practice and Emergency Medicine ${ }^{1}$, Department of Psychiatry ${ }^{2}$, Department of \\ Internal Medicine ${ }^{3}$, B.P. Koirala Institute of Health Sciences, Dharan, Nepal
}

\begin{abstract}
Background: The term chronic headache is commonly taken as headache lasting for more than three months. It is common in general practice with minimal research on the topic in Nepal. Objective: To sort out the common diagnoses of chronic headache and to study the clinical features and demographic profile of patients presenting with chronic headache. Method: A descriptive cross sectional study was conducted (2012 August to 2013 August) at General Practice outpatients in BP Koirala Institute of Health Sciences, a medical university in eastern Nepal. Approval and ethical clearance was taken from Research Committee and Institutional Ethical Review Board. Descriptive statistical analysis was done. Result: 168 patients constituting $1 \%$ of outpatient visits presented due to chronic headache. Mean age was 29.57 years (SD 10.53) and female to male ratio was 3.67. Mean number of days of headache was 19.46 days (SD 4.62). Numerical pain score was reported at 7.1/10 (SD 1.85). The mean duration of presentation was 22 months (SD 11). 40\% reported impaired activity of more than one week. Headache was classified as chronic migraine in $20.2 \%$, chronic tension type headache in $16.7 \%$, and chronic daily persistent headache in $11.9 \%$. The diagnosis did not fit into any diagnostic criteria in $51.2 \%$ cases. Conclusion: Chronic headache is common in females and young age group. Patients present late despite significant pain scores. Significant proportion is still unclassified.
\end{abstract}

Keywords: Chronic headache, general practice, Nepal.

\section{Introduction}

The term chronic headache has not been

\section{Address for correspondence}

Rabin Bhandari

Additional Professor

Department of GP \& EM

B.P. Koirala Institute of Health Sciences, Dharan

Email: bhandari529@yahoo.com defined formally by the International Headache Society. But it is commonly taken as headache lasting for more than three months. ${ }^{1,2}$ Primary daily chronic headaches major subgroups are chronic migraine, chronic tension type headache, hemicrania 
continua and new persistent daily headache. ${ }^{1,2,3}$ Among these chronic migraine (sub classified as complication of migraine) and chronic tension type (evolving from episodic migraine) need to be present for more than 15 days per month. ${ }^{2}$ Chronic headache is a common problem in both specialist care and primary care setting ${ }^{4}$ and contributes to low quality of life. It is also a cause of social and economic burden. ${ }^{1,6}$ The global prevalence of headache is estimated at $47 \% .{ }^{6}$ General practitioners frequently see the patient with headache first. ${ }^{7,8}$ Literature from South East Asian countries like India and Pakistan have shown tension type headache and migraine to be the commonest cause for chronic headache..$^{9,10}$ Researches on headache from Nepal are limited with none on chronic headache in general practice. Headache diagnoses have been found among common diagnostic correlates in diagnostic profile studies of psychiatric patients of our hospital in different settings, such as referred out-patients, ${ }^{11}$ child and adolescent out-patients ${ }^{12}$ and mass health camp settings. ${ }^{13}$

We conducted a study in the general practice outpatient department with an aim to sort out the common diagnoses of chronic headache and to study the clinical features and demographic profile of patients presenting with chronic headache.

\section{Methods}

A descriptive cross sectional study was conducted among the patients presenting with chronic headache to the General Practice outpatient at B.P. Koirala Institute of Health Sciences (BPKIHS) over one year from 2012 August to 2013 August. The general practice outpatients see an average of 100 unsorted case mix per day.

All patients presenting with complains of chronic headache were included and interviewed by one of the researchers using a pre formed questionnaire. The patients were managed by their respective physicians and researchers did not interfere with patients' plan of management. The term chronic was defined as duration of more than three months and diagnostic criteria from 'The international classification of headache disorder, 2nd edition (ICHD 2) ${ }^{3}$ was used to classify headache.

Severity of headache was assessed using numerical scale from one to ten.

Other variables studied were demographic profile and clinical features. Patients were also called for a one time follow up within one month.

Informed consent was taken from all the patients and strict confidentiality was maintained during one on one interview. Approval for the study and ethical clearance was taken from Research Committee and Institutional Ethical Review Board, BPKIHS. 
SPSS and EPI info software was used for statistical analysis. Categorical variables were presented as percentages with $95 \% \mathrm{Cl}$. Numerical variables were presented as mean with standard deviation $(95 \% \mathrm{Cl}$ with lower and upper bound values). Cross tabulation of gender, marital status (unmarried, married, separated) occupation (housewife, students, others) and educational status (illiterate, upto 10 years of school, more than 10 years of school) was done among different subtypes of headache.

Table 1: Characteristics of patients under study $(n=168)$

\begin{tabular}{|l|l|}
\hline Age & $\begin{array}{l}\text { Mean 29.57 years } \\
\text { (SD 10.53, 95\% Cl 27.97- } \\
31.18)\end{array}$ \\
\hline Sex & $\begin{array}{l}\text { Male 21.4\% } \\
\text { Female 78.6\% }\end{array}$ \\
\hline Occupation & $\begin{array}{l}\text { Housewife 51.2\% } \\
\text { Students 26.2\% } \\
\text { Others 22.6\% }\end{array}$ \\
\hline Education & $\begin{array}{l}\text { Illiterate 22.6\% } \\
\text { Up to 10 years 53.6\% } \\
\text { More than 10 years 23.8\% }\end{array}$ \\
\hline Marital status & $\begin{array}{l}\text { Married 60.7\% } \\
\text { Unmarried 35.7\% } \\
\text { Separated 3.6\% }\end{array}$ \\
\hline Religion & $\begin{array}{l}\text { Hindu 76.8\% } \\
\text { Buddhism 8.9\% } \\
\text { Christian 10.1\% }\end{array}$ \\
\hline
\end{tabular}

\section{Results}

A total of 168 patients presented with chronic headache over a period of 1 year, accounting for $1 \%$ of total general outpatient visits. The mean age of the patients under study was 29.57 years (SD 10.53). The female: male ratio was 3.67 . Majority were married $(60 \%$, $95 \% \mathrm{Cl}$ 53-68). Occupation was listed as housewives by $51 \%(95 \% \mathrm{Cl} 43-59)$ and students by $26 \%$ (95\% Cl 19-33). Majority of patients had chosen to visit hospital themselves (95\%, 95\% Cl 91-98), 4 patients were referred from other hospitals. (Table 1)

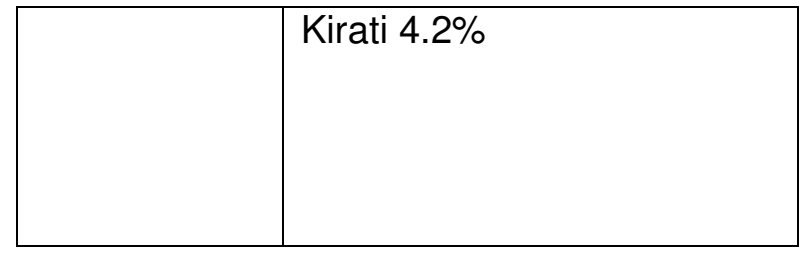

The mean duration of headache before consultation by a doctor was 22 months (SD 11). The mean number of days with headache per month was 19.46 days (SD 4.62). Impairment of routine work due to headache was reported by 78 patients (46\%, $95 \% \mathrm{Cl} 39-54)$. In this group, the average number of days off work per month was 3.67 days per month(SD 5.32, minimum 0 , maximum 21). The mean score for pain (numerical scale) was 7.1 (SD 1.85).

The headache was classified as chronic migraine in 34 patients (20.2\%), chronic tension type headache in 28 (16.7\%) and chronic daily persistent headache in 20 
(11.9\%). Patients did not fit into any diagnostic criteria in 86 (51.2\%) cases.

The mean age was 33.62 years (SD 9.368, 95\% Cl 30.35-36.89) in chronic migraine, 26.11 (SD 5.412, 95\% Cl 24.01-28.21) in tension type headache, 27.55 (SD 8.870, 95\% Cl 23.40-31.70) in chronic persistent daily headache and 29.57 (SD 12.066, 95\% Cl 26.98-32.16) in unclassified group.

The mean duration to doctors visit was 26.41 months (SD 9.897, 95\% Cl 22.96-29.860) in chronic migraine, 21.64 (SD 9.569, 95\% Cl 17.93-25.35) in tension type headache, 19.80 (12.639, 95\% Cl 13.88-25.72) in daily persistent headache and 21.41 (SD 11.289, $95 \% \mathrm{Cl} 18.99-23.83)$ in the unclassified group.
The mean pain score was 7.79 (SD 1.175, 95\% Cl 7.38-8.20) for chronic migraine, 7.36 (SD 1.569, 95\% Cl 6.75-7.97) for tension type headache, 6.9 (SD 2.360, 95\% Cl 5.8-8.00) for daily persistent headache and 6.79 (SD 1.965, $95 \mathrm{Cl} 6.37-7.21)$ for the unclassified group.

Different subtypes of chronic headache were cross tabulated with gender, educational status, marital status and occupation. Marital status and occupation showed statistical significance when compared with the subtypes of headaches. Gender and education did not show statistical significance. (See table 2)

Table 2: Comparison of headache classification and population characteristics

\begin{tabular}{|c|c|c|c|c|c|}
\hline Characteristics & $\begin{array}{c}\text { Chronic } \\
\text { Migraine } \\
\text { (34) }\end{array}$ & $\begin{array}{c}\text { Chronic } \\
\text { Tension } \\
\text { type } \\
(28)\end{array}$ & $\begin{array}{c}\text { Chronic } \\
\text { persistent } \\
\text { daily (20) }\end{array}$ & $\begin{array}{c}\text { Unclassified } \\
\text { (86) }\end{array}$ & P value \\
\hline $\begin{array}{l}\text { Gender } \\
\text { Male } \\
\text { Female }\end{array}$ & $\begin{array}{l}5(14.7 \%) \\
29(85.3 \%)\end{array}$ & $\begin{array}{l}9(32.1 \%) \\
19(67.9 \%)\end{array}$ & $\begin{array}{l}5(25 \%) \\
15(75 \%)\end{array}$ & $\begin{array}{l}17(21.4 \%) \\
69(80.2 \%)\end{array}$ & 0.374 \\
\hline $\begin{array}{l}\text { Education } \\
\text { Illiterate } \\
<10 \text { years } \\
\text { >10 years }\end{array}$ & $\begin{array}{l}8(23.5 \%) \\
18(52.9 \%) \\
8(23.5 \%)\end{array}$ & $\begin{array}{l}4(14.3 \%) \\
13(46.4 \%) \\
11(39.3 \%)\end{array}$ & $\begin{array}{l}4(20 \%) \\
12(60 \%) \\
4(20 \%)\end{array}$ & $\begin{array}{l}22(25.6 \%) \\
47(54.7 \%) \\
17(42.5 \%)\end{array}$ & 0.514 \\
\hline
\end{tabular}




\begin{tabular}{|c|c|c|c|c|c|}
\hline $\begin{array}{l}\text { Marriage } \\
\text { Unmarried } \\
\text { Married } \\
\text { Separated }\end{array}$ & $\begin{array}{l}5(14.7 \%) \\
25(73.5 \%) \\
4(11.8 \%)\end{array}$ & $\begin{array}{l}12(42.9 \%) \\
16(57.1 \%) \\
0\end{array}$ & $\begin{array}{l}8(40 \%) \\
12(60 \%) \\
0\end{array}$ & $\begin{array}{l}35(40.7 \%) \\
49(57 \%) \\
2(2.3 \%)\end{array}$ & $\begin{array}{l}0.021 \\
\text { Chi } \\
\text { Square } \\
14.959(6)\end{array}$ \\
\hline $\begin{array}{l}\text { Occupation } \\
\text { Housewife } \\
\text { Student } \\
\text { Others }\end{array}$ & $\begin{array}{l}24(70.6 \%) \\
0 \\
10(29.4 \%)\end{array}$ & $\begin{array}{l}10(35.7 \%) \\
10(35.7 \%) \\
8(28.6 \%)\end{array}$ & $\begin{array}{l}8(40 \%) \\
6(30 \%) \\
6(30 \%)\end{array}$ & $\begin{array}{l}44(51.2 \%) \\
28(32.6 \%) \\
14(16.3 \%)\end{array}$ & $\begin{array}{l}0.005 \\
\text { Chi } \\
\text { square } \\
18.757(6)\end{array}$ \\
\hline
\end{tabular}

A onetime follow up within a month was planned. It was attended by $16.7 \%$ patients. During the follow up visit of these patients the mean numerical pain score had decreased by 3.11 (SD 1.72).

\section{Discussion}

Headache is also one of common condition presenting to primary health care, with estimates of $3-4 \% \%^{14,15,16}$ of population suffering from chronic headache. Most of the data are extrapolated from western population. Few population-based studies exist for developing countries where limited funding and large and often rural populations, coupled with the low profile of headache disorders compared with other diseases, prevent the systematic collection of information. ${ }^{6}$ Our study provides a snapshot of chronic headache in the general practice outpatient department (OPD) of a country with predominantly rural population. The patients presenting to general practice OPD in our institute is reflective of primary care setting combined with referred patients from outside. It is first contact to hospital in a large number of presentations. Chronic headache formed $1 \%$ of our OPD presentation which is lesser than population estimates. However, actual number of patients is probably higher. Many patients with headache may visit the specialty clinics directly. ${ }^{4,8}$ A fractions of patient also visits the local pharmacies, auxiliary health workers, local practitioners including complementary and alternative medicine $^{8}$ before visiting the hospital. The same practice could also explain the long wait (22 months) before a patient contacted a doctor for the problem. Difficult geopolitical conditions of our country may also have contributed to seemingly lower prevalence and delayed presentation of the patients.

The predominant age involved was young with impaired routine activity reported by more than $50 \%$ of patients. Gender wise, females were common. Similar findings for headache in general including chronic headache have been reported. . $^{4-9,15,17,18}$ 
However, the gender ratio of 3.6 reported in our study is comparatively higher than reported previously. Females are socio culturally more vulnerable with lower literacy rates. So, they may be prone to present late to doctors with more complex presentations in our set up.

Chronic migraine and chronic tension type headache have been reported as commonest chronic headache types..$^{9,10,15,17,18}$ Although the diagnosis of chronic migraine, chronic tension type headache and persistent daily headache were almost evenly distributed in our study, the proportion of unclassified headache was almost $50 \%$. This is in contrast to study by Agarwal et $\mathrm{al}^{18}$ reporting $1.9 \%$ unclassified headache but compares favorably to Beghi et $\mathrm{al}^{4}$ who reported $27 \%$ unclassified chronic headache by general practitioners overall, and $78 \%$ in Southern Italy. Irrespective of the headache category all the patients reported moderate to severe chronic pain and a significant proportion had impaired regular activity needing attention. When called for follow up, only $17 \%$ attended the follow up. This suggests a further scope for research involving the community level workers in the management of complex problems like long standing headaches. In countries like Nepal with uneven distribution of health resources, ${ }^{19}$ it allows an opportunity to train and coordinate chronic pain care with local health workers.

\section{Limitation}

The study has tried to provide a snapshot of chronic headache picture in general practice outpatients and may not be reflective of larger populations.

\section{Conclusions}

Chronic Headache is common in young females. The patients often present late to hospitals. A signification proportion was unclassified. Coordinated and continued care of chronic pain involving local community workers may be useful as the case mix is largely unclassified, present late to a doctor and has low follow up rate.

\section{References}

1. Morimatsu M. Classification of Chronic Headache. JMAJ 2004;47(3): 112-117

2. International Headache Classification Subcommittee of the International Headache Society. The International Classification of headache disorder. $2^{\text {nd }}$ edition. Cephalalgia 2004; 24 Suppl 1: $1-150$

3. Silberstein S. Chronic Daily Headache. JAOA 2005; 105 (4) Suppl 2:23-29

4. Beghi E, Monticelli ML, Amoruso L, Zarrelli MM \& the Italian General Practitioner Study Group. Prevalence, characteristics, and patterns of health care use for chronic headache in two areas of Italy. Results of a 
questionnaire interview in general practice. Cephalalgia2003; 23 (3): 175182.

5. O'Flynn N, Ridsdale L. Headache in primary care: how important is diagnosis to management? $\mathrm{Br} \mathrm{J}$ Gen Pract. 2002 Jul (52):569-573.

6. WHO media center [Internet]. Headache disorders. Factsheet no. 227. [updated 2012 Oct; cited 2012 Nov 13]. Available from: http://www.who.int/mediacentre/factshe ets/fs277/en/

7. Frese $T$, Druckrey $H$, Sandholzer $H$. Headache in General Practice: Frequency, Management, and Results of Encounter. International Scholarly Research Notices [Internet].2014 Oct [cited 2014 Nov 28]. 2014: 169428. Available from: http://dx.doi.org/10.1155/2014/169428

8. Kristoffersen ES, Grande RB, Aaseth K, Lundqvist C, Russell MB. Management of primary chronic headache in the general population: The Akershus study of chronic headache. J Headache Pain 2012; 13:113-120

9. Murtaza $M$, Kisat $M$, Daniel $H$, Sonawalla AB. Classification and Clinical Features of Headache Disorders in Pakistan: A Retrospective Review of Clinical Data. Cookson MR, editor.[Internet] PLoS ONE. 2009 Jun [cited 2014 Nov 28]; 4(6): e5827. Available from: http://journals.plos.org/plosone/article?i $d=10.1371 /$ journal.pone.0005827

10. Chakravarty A. Chronic daily headaches: Clinical profile in Indian patients. Cephalalgia 2003; 23(5): 34853.

11. Shakya DR, Pandey AK, Shyangwa PM, Shakya R. Psychiatric morbidity profiles of referred Psychiatry OPD patients in a general hospital. Ind Med J. 2009 Dec; 103(12): 407- 411.

12. Shakya DR. Psychiatric morbidity profiles of Child and adolescent Psychiatry out-patients in a tertiary-care hospital. J Nepal Paediatr Soc. 2010, 30(2):79-84.

13. Shakya DR. Psychiatric morbidity pattern in a health camp in eastern Nepal. J Health Renaissance 2010; 8(3):186-191.

14. Scher Al, Stewart WF, Liberman J, Lipton RB. Prevalence of frequent headache in a population sample. Headache. 1998; 38: 497-506.

15. Castillo J, Munoz P, Guitera V, Pascual J. Epidemiology of chronic daily headache in the general population. Headache. 1999; 39: 190-196.

16. Wang SJ, Fuh JL, Lu SR, Liu CY, Hsu LC, Wang PN, Liu HC. Chronic daily headache in Chinese elderly: 
Prevalence, risk factors and biannual follow-up. Neurology. 2000; 54: 314319.

17. El-Sherbiny NA, Masoud M, Shalaby NM, Shehata HS. J Headache Pain 2015; 16: 85

18. Agarwal V, Chaurasia RN, Mishra VN, Joshi D, Misra S. International Journal of General Medicine and Pharmacy 2013; 2(3): 9-14.

19. Ministry of Health and Population, Nepal. Human Resource for Health Nepal Country Profile [updated Aug 2013. cited $10^{\text {th }}$ September 2015]. Available from: http://www.nhssp.org.np/human_resourc es/HRH\%20profile\%20\%28QA\%29.pdf 